\title{
RUMEN CANNULATION OF SHEEP BY HECKER METHOD - A CASE STUDY
}

\author{
K. Nizanantha ${ }^{1}$, W.M.N.K. Jayathilake ${ }^{1}$, M.W.I.N.B. Makuloluwa ${ }^{1}$, \\ W.M.T.D. Rathnakumara ${ }^{1}$ and W.M.P.B. Weerasinghe ${ }^{2}$ \\ ${ }^{1}$ Department of Farm Animal Production and Health, Faculty of Veterinary Medicine and Animal \\ Science, University of Peradeniya, ${ }^{2}$ Sri Lanka Veterinary Research Institute, Gannoruwa, \\ Peradeniya, Sri Lanka
}

\begin{abstract}
SUMMARY: A modified fistulation technique described by Hecker in 1969 was adopted for the first time in Sri Lanka in sheep, in order to establish a cannulated rumen fistula. Pre-operative procedures included administration of tetanus toxoid 14 days prior to surgery, withholding feed and water for twenty-four hours, Vitamin B-complex and antibiotic injections on the day prior to surgery, and preparation of the left flank region for surgery. Immediately prior to the surgery parenteral analgesic injection was administered and left para-vertebral nerve block was performed. The rumen wall was exteriorized through a laparotomy incision and a metal clamp was applied. Simple interrupted sutures were placed using nylon through the skin, rumen wall and the clamp. After 7 -9 days the exteriorized rumen wall sloughed off leaving a fistula. A tight rubber cannula was inserted through the fistula and the cannula was closed with a ring and stopper. The antibiotic and analgesic were repeated post-operatively for three days. The cannulated animals were used for a one-year research project and the animals were clinically normal throughout the project.
\end{abstract}

\section{INTRODUCTION}

Evaluation of the digestible components of the diets of grazing animals has been emphasized by various nutritionists, physiologists and pathologists (Phillipson and Innes, 1939). As the quality and the quantity of the ruminal fluid obtained via a stomach tube are inadequate, an alternative method for collecting the ruminal fluid was preferred (Harmon and Richards, 1997).

Rumen cannulation is a minimally invasive technique which allows access to the rumen for in vitro and in vivo studies (Sedeek and Suliman, 2007). The first successful ruminal fistulation was performed by Colin in 1886 in an ox, but the fistula was not closed by mechanical means (Phillipson and Innes, 1939). The same procedure was followed by Schalk and Amadon in 1928 in cattle and an attempt was made to close the fistula using a block of wood (Phillipson and Innes, 1939). Over the years modifications and new evolutions of these methods have taken place (Phillipson and Innes, 1939).

Open fistulae have been used in ruminants for digestibility trials for a long period of time, but it has shown some disadvantages, including unsightly appearance and unsatisfactory carrying out of physiological work after fistulation (Grovum, 1988). Open ruminal fistulae also allow loss of water, electrolytes, nitrogen and organic matter, which is another main drawback, leading to loss of weight and body condition of the animals (Grovum, 1988;
Phillipson and Innes, 1939). Animals with open fistulae are difficult to maintain and usually look and smell bad, thus they should be cleaned daily and measures should be taken to minimize fly attraction (Grovum, 1988).

Even though the cannulation is considered to be a less invasive measure to gain access to the rumen, there are various possible post-surgical complications including leakage from cannulas (Grovum, 1988; Rafee et al., 2015). There were various methods devised to stop the leaks such as wrapping cotton wool around the cannula stem from the outside, which usually separates the cannula and the fistula, but these were proven to be unsuccessful(Grovum, 1988).

Thus, the objective of this study was to use a modified fistulation method described by Hecker in 1969 in sheep, in order to establish a cannulated rumen fistula and to minimize the possible drawbacks mentioned above.

\section{CASE PRESENTATION AND SURGICAL PROCEDURE}

Selection of the Animals:

Clinically normal, three Red Madras male sheep over one and a half years of age were selected for the study. Tetanus toxoid was given 14 days prior to the surgery. Two days prior to the surgery the selected sheep were brought to the Department of Farm Animal Production and Health, University of Peradeniya and were provided with ad libitum access to feed and water. 
Preparation of the animals: 24 hours before surgery

Feed and water were restricted for twenty-four hours prior to the surgery. Vitamin B complex (BioB.Complex ${ }^{\circledR}$, Bio-Pharmachemie, Vietnam) $5 \mathrm{ml}$ and long acting prophylactic antibiotic Oxytetracycline (Limoxin-200 LA, Interchemie werken, Holland) 20 $\mathrm{mg} / \mathrm{kg}$ were administered intramuscularly. The left flank region was clipped and shaved.

\section{Preparation of the animals: on the day of the surgery}

An analgesic Flunixin hydrochloride (fiveFLUNIXIN $^{\mathbb{B}}$, 'fivevet', Vietnam) $2 \mathrm{mg} / \mathrm{kg}$ was administered intramuscularly prior to the surgery. Animal was gently restrained, brought to the operation theater and placed in right lateral recumbency on the surgical table. The ends of the L1, L2 and L4 transverse processes of lumbar vertebrae were located and the skin over the landmarks was disinfected.

Four millilitres of $2 \%$ lignocaine hydrochloride ANASICA $^{\mathrm{TM}}$, Ambalal Sarabhai Enterprises Ltd, India) was injected below each of the L1, L2 and L3 transverse processes using a $21 \mathrm{G}$ hypodermic needle in a fanwise fashion in order to locally anesthetize the surgical site. The area was allowed to lose its sensitivity to pain over a period of 5-10 minutes. Using blunt forceps, the area was tested to ensure adequacy of anesthesia.

\section{Surgical procedure}

A modified fistulation method for sheep described by Hecker in 1969 was used for all sheep. The standard surgical procedure issued by The University of Western Australia (2013) was followed for the cannulation of all animals.

The surgical site was scrubbed three times alternatively, with chlorhexidine (1\%), isopropyl alcohol $(70 \%)$ followed by application of Povidone Iodine $(10 \%)$ in a progressive manner towards the margins of the shaved area starting from the site of incision. The surgical site was covered with sterile surgical drapes. The level of local anesthesia was confirmed to be adequate as pinching along the incision line using blunt forceps did not cause skin twitching. An initial $2.5 \mathrm{~cm}$ cranio-caudal skin incision was placed $6-7 \mathrm{~cm}$ caudal to the last rib and $5-6 \mathrm{~cm}$ from the spinous processes of the lumbar vertebrae, using a sterile scalpel. Abdominal muscle layers were cut and the peritoneum was grasped using a rat tooth forceps and was incised to expose the abdominal cavity. The rumen was located and palpated with thumb and fore finger to feel the rumen papillae in order to confirm that the rumen was correctly identified. A metal clamp was fitted over the exposed part of the exteriorized rumen and the clamp was tightened to occlude the blood supply to the exteriorized part. Two to three full thickness simple interrupted sutures were placed using nylon through the skin, rumen wall and the clamp to ensure firm adhesion of rumen to the edges of the skin and to prevent the clamp from falling off (Figure 1).
The animal was lifted from the theater table and moved to a clean pen.

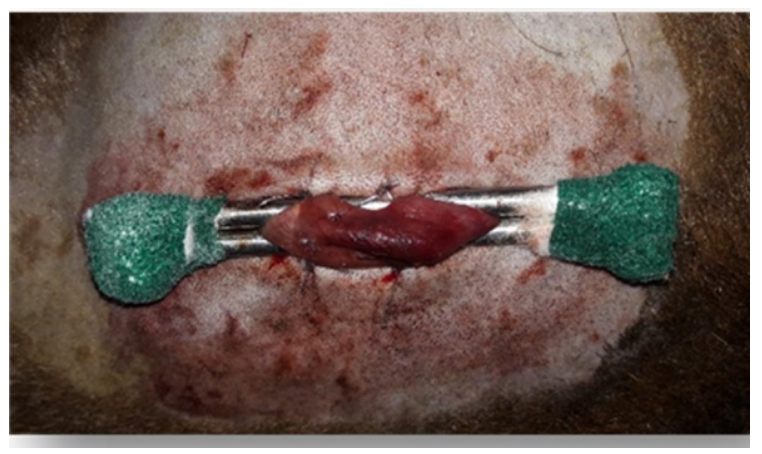

Figure 1: Metal clamp fixed to the exteriorized rumen fold and skin

\section{Post-operative care: Day 02-07}

The animals were closely monitored and were provided with ad libitum feed and water. Flunixin hydrochloride (five-FLUNIXIN ${ }^{\circledR}$, 'fivevet', Vietnam) $1.1 \mathrm{mg} / \mathrm{kg}$, intramuscular injection was repeated after 24 hours of surgery and two doses of Oxytetracycline (Limoxin-200 LA, Interchemie werken, Holland) 20 $\mathrm{mg} / \mathrm{kg}$, intramuscular injection was repeated every other day. The exteriorized rumen sloughed off after $7-$ 9 days leaving a fistula (Figures 2 and 3 ).

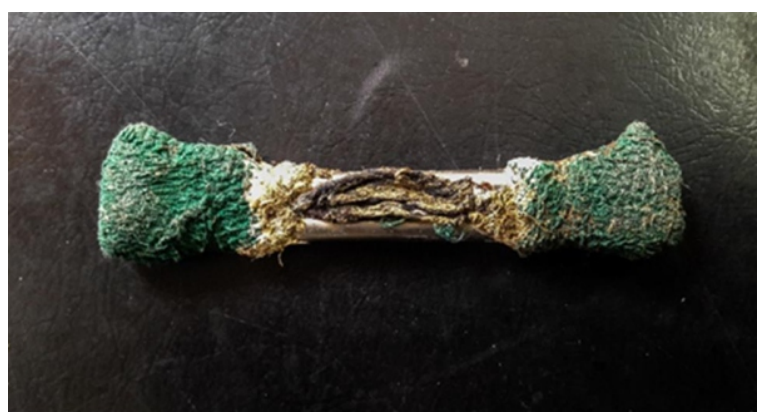

Figure 2: Sloughed off rumen fold along with the metal clamp

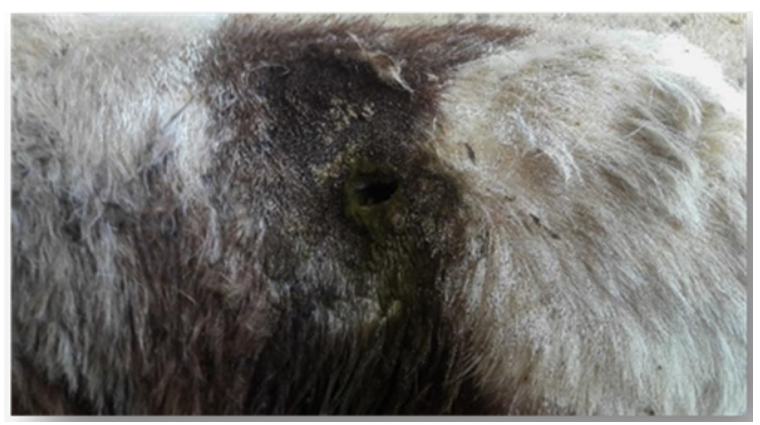

Figure 3: Rumen fistula after sloughing off of the exteriorized rumen wall 


\section{Insertion of the cannula: Day 07-09}

The rubber cannula (Figure 4) was turned inside out and both internal and external surfaces were lubricated well using liquid paraffin. The fistula was cleaned and Lignocain Hydrochloride (Lidoright ${ }^{\circledR}$ 2\%) ointment was applied around the fistula. After 5-10 minutes of resting period to allow the area to get desensitized, the internal flange of the cannula was inserted in to the fistula.

The cannula was gently unfolded inside the rumen (Figure 4). A Perspex ring was placed over the cannula (Figure 5). The opening was closed using an appropriately sized PVC tube and sealed using a rubber stopper (Figure 6). Flunixin hydrochloride (five-FLUNIXIN ${ }^{\circledR}$, 'fivevet', Vietnam) $1.1 \mathrm{mg} / \mathrm{kg}$, intramuscular injection was administered and the animal was kept in a quiet pen and was closely monitored.

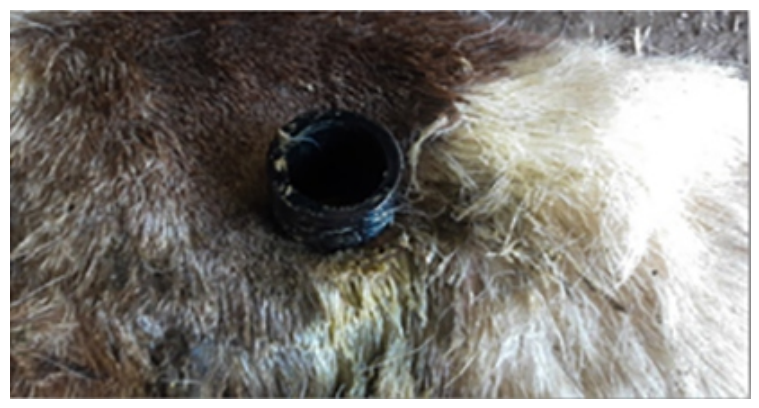

Figure 4: Rubber cannula inserted in to the fistula

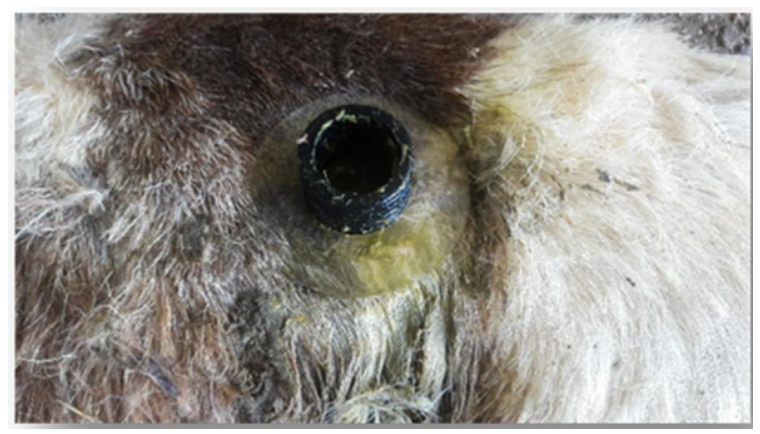

Figure 5: A Perspex ring applied over the rubber cannula

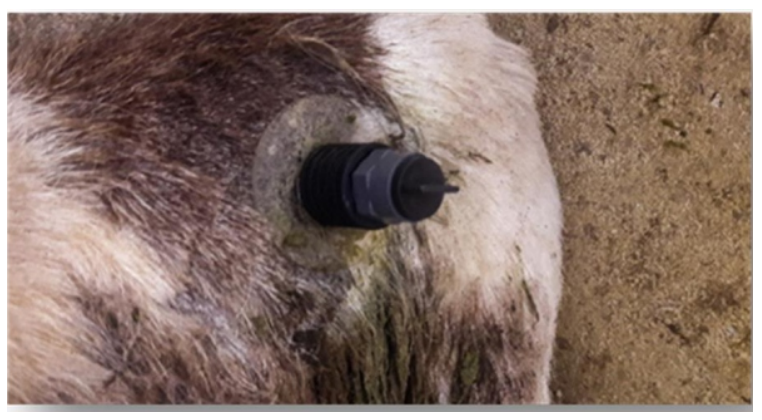

Figure 6: Rubber cannula closed using a PVC tube and a rubber stopper

\section{OUTCOME OF THE SURGERY}

The cannulated animals were used for a one-year research project. They were kept under intensive management and they showed normal health, appetite and behavior throughout the project. Therefore, this method of cannulation is considered to be successful.

\section{DISCUSSION AND CLINICAL SIGNIFICANCE}

As nutrition has a direct relationship with the production of the animals, many feed trials have taken place using cannulated animals in order to enhance production by changing the feeding patterns. In the Sri Lankan context, feeding of the animal is a factor which can be easily manipulated even by the farmers with a lower economical background. Therefore, using such a technique will allow us to investigate different feed trials with the aim of enhancing the livestock production in Sri Lanka. This method can be used also in research on pathology in order to broaden the knowledge on the patho-physiology affecting mainly the digestive tract.

Open fistulae have shown some disadvantages including leakage of ruminal content. In Hecker method, using a cannula with a rubber stopper prevents possible leakage of ruminal content and thus reduces the complications associated with an open fistula. Therefore, the cannulated animals perform and live a better life post surgically than the fistulated animals.

When compared to the other available methods for rumen cannulation, Hecker method prevents leakage of ruminal content in to the peritoneal cavity, as the ruminal wall is allowed to attach to the body wall and eventually slough off, without leaving space for such leakage. Therefore, by using this method the risk of post-surgical peritonitis can be reduced.

Even though a cannula is inserted to close the fistulae, there is a possibility of leakage (Grovum, 1988; Rafee et al., 2015). In Hecker method, by using a cannula which can be closed using a rubber stopper and by inserting a Perspex ring over the cannula, possible leakages were minimized and the body condition of the animals can be maintained after the cannulation is done.

Several important factors should be considered before and after the procedure. Animals with a docile temperament should be selected, as excitable animals could end up with self-inflicted trauma after the surgery or during sampling. Starving the animal for twentyfour hours prior to the surgery helps in easily grasping the rumen wall. After the surgery the animals should be kept in individual pens to minimize injuries. Close post-operative monitoring is important to detect any changes in the animals and to detect the sloughing off of the exteriorized rumen fold. Allowing access to water and some hay could stimulate the rumen function after the surgery. The surgical site should be evaluated on a daily basis for any signs of swelling, bleeding, infection or fly attraction and should be immediately intervened. The wound can be cleaned and dressed with an 
antiseptic preparation and a fly repellent. Any behavioral changes of the animals should be immediately investigated by a veterinarian. If the cannula comes off the fistula accidently it should be reinserted immediately to prevent leakage of ruminal content.

\section{CONCLUSION}

Hecker method has not been previously used in Sri Lanka for rumen cannulation. This case study confirms that Hecker method is a successful procedure for rumen cannulation and can be used in future experiments in Sri Lanka.

\section{AKNOWLEDGEMENT}

Authors would like to acknowledge Mr. M.B.P. Kumara Mahipala, Mr. T. Thelakshan and Ms. W.V.A.H. Chathurika of the Department of Animal Science, Faculty of Agriculture, University of Peradeniya; Dr. H.T.S.I. Madushanka, Dr. Y. Prashanth and academic and non-academic staff of the Department of Farm Animal Production and Health, Faculty of Veterinary Medicine and Animal Science, University of Peradeniya; and BVSc undergraduate students of the 2012/2013 batch.

The research project was supported by the National Research Council (NRC TO 14-10)

\section{REFERENCES}

Grovum, W.L. (1988). Inserting a rumen cannula in sheep to minimize leakage. Canadian Journal of Animal Science, 68: 561-563.

https://doi.org/10.4141/cjas88-063

Harmon, D.L. and Richards, C.J. (1997). Considerations for gastrointestinal cannulations in ruminants. Journal of Animal Science, 75: 2248-2255. https://doi.org/10.2527/1997.7582248x

Hecker, J.F. (1969). A simple rapid method for inserting rumen cannulae in sheep. Australian Veteterinary Journal, 45: 293-294.

https://doi.org/10.1111/j.1751-0813.1969.tb01954.x

Phillipson, A.T. and Innes, J.R. (1939). Permanent stomach fistulae in ruminants. Journal of Experimental Physiology and Cognate Medical Sciences, 29: 333-341.

https://doi.org/10.1113/expphysiol.1939.sp000

Rafee, M.A., Sinha, S. and Saxena, A. (2015). Fistulation and cannulation of the rumen in buffaloes: comparision of two methods. International Journal of Veterinary Health Science Research, 3: 64-65.

https://doi.org/10.19070/2332-2748-1500016
Schalk, A. and Amadon R. S. (1928). Physiology of the ruminant stomach (bovine). North Dakota Agricultural Experimental Station Bulletin, 216.

Sedeek, A.M. and Suliman, A.I.A. (2007). An effective device for rumen cannulation in sheep. Animal Care and Use Committee, 53: 18-23. 